\title{
Isolation and Long Term Preservation of Pancreatic Islets from Mouse, Rat and Guinea Pig
}

\author{
J. Ferguson, R.H. Allsopp, R.M.R. Taylor and I.D. A. Johnston \\ Dept. of Surgery, Univ. of Newcastle upon Tyne, Newcastle upon Tyne, England
}

Summary. This paper reports techniques for the isolation and long term preservation of pancreatic islets from the mouse, rat and guinea pig. Islets have been isolated using a modification of a free hand microdissection procedure described by Hellerström in 1964 [1]. Isolated islets have been subjected to three preservation systems and their viability following storage assessed by light microscopy of sections stained with Gomori's aldehyde fuchsin [2] and by measuring the insulin release from islets in vitro in response to a glucose stimulus.

The systems were: a) Simple cold storage in Hank's balanced salt solution at $4^{\circ} \mathrm{C}$. Following $15 \mathrm{~h}$ cold storage, histological and functional survival was $100 \%$. This dropped to $10 \%$ at $48 \mathrm{~h}$. There were no survivors following $72 \mathrm{~h}$ storage. b) Sub zero cell storage. In Group I (freezing rate $1^{\circ} \mathrm{C} / \mathrm{min}$ ) histological survival was $35 \%$ and functional survival $20 \%$. In Group II (freezing rate $5^{\circ} \mathrm{C} / \mathrm{min}$ with $24 \mathrm{~h}$ culture period after rewarming) histological survival was approximately $87 \%$ and functional survival $75 \%$. c) Organ Culture. Islets from the guinea pig, rat and mouse showed minimal morphologic damage when cultured for 21 days in a simple organ culture system. At 28 days, histological survival was approximately $30 \%$. Following organ culture we were unable to correlate histological and functional survival.

Key words: Pancreatic islets, microdissection, preservation, cold storage, cryopreservation, organ culture, perifusion.

Several workers have reported amelioration of the diabetic state in animals following the implantation of collagenase isolated islets into a variety of sites in- cluding muscle, peritoneum [3] and more recently into the portal vein [4].

The main criticism of islet cell transplantation is that at the present time there are no satisfactory methods available for harvesting large numbers of islets from any one pancreas. Freehand microdissection of islets described by Hellerström in 1964 [1] is tedious, time consuming and the yield is low. The collagenase digestion method described by Lacy and Kostianovsky [5] produces a greater yield but this method contains several steps which theoretically may damage the islets; these include the potent enzyme collagenase, digestion at $37^{\circ} \mathrm{C}$, centrifugation and finally, hyperosmolar sucrose solutions used in the final steps of isolation. Ruiz and Lillehei [6] state that only $5-10 \%$ of islets remain viable after collagenase isolation. Lacy [5] comments that the collagenase plus centrifugation technique should not be used if isolated islets are required for in vitro metabolic studies.

One solution to the problem of small yield would be the establishment of successful long term preservation methods for isolated islets.

This paper reports our investigation of three preservation systems using microdissected islets from the mouse, rat and guinea pig.

a) Simple cold storage of islets in a balanced salt solution at $4^{\circ} \mathrm{C}$.

b) Sub zero storage of islets in liquid nitrogen at $187^{\circ} \mathrm{C}$.

c) Organ culture of isolated islets.

\section{Materials and Methods}

\section{Animals}

Mice, rats and guinea pigs have been used without regard to age, sex or weight. All animals were starved for 48 hours prior to pancreatectomy. 


\section{Isolation of Islets}

Islets were isolated using a modification of the free hand microdissection procedure described by Hellerström [1]. The donor animal was killed and the pancreas quickly removed by dissection. The excised pancreas was then diced into small pieces measuring approximately $2 \mathrm{~mm} \times 2 \mathrm{~mm}$, which were subsequently washed several times with cold Hank's solution. The diced pancreas was transferred to the dissection well containing $8.0 \mathrm{ml}$ of Hank's solution at $4^{\circ} \mathrm{C}$. This temperature was maintained by passing a water-antifreeze mixture at $-1^{\circ} \mathrm{C}$ through an outer hollow chamber surrounding the well. Microdissection of islets was then carried out using a Wild stereo dissecting microscope with oblique incident illumination against the black background of the dissection well. Under the microscope islets appear as dense white ovoid bodies, often closely related to ducts. Separation of the islets from surrounding acinar tissue was performed with watchmakers forceps and a cataract knife. The dissection was normally completed within $45 \mathrm{~min}$.

\section{Simple Cold Storage}

Microdissected islets in groups of ten were transferred from the dissection well to small glass tubes containing Hank's balanced salt solution at $4^{\circ} \mathrm{C}$. The transfer was performed with a small wire loop. The tubes were placed in a refrigerator at $4^{\circ} \mathrm{C}$ for periods varying from 15 to $72 \mathrm{~h}$.

\section{Storage in Liquid Nitrogen at $-187^{\circ} \mathrm{C}$}

We have used a Cryosan biological freezer, model BV4. Once again islets in groups of ten were transferred from the dissection well with the aid of a wire loop. They were placed in a freezing mixture made up as follows: Earles solution, $10 \%$ dimethyl sulphoxide (D.M.S.O.) and $10 \%$ fetal calf serum in small polythene cryules.

In the first thirteen experiments (Group I) the freezing rate was $1^{\circ} \mathrm{C} / \mathrm{min}$ to $-50^{\circ} \mathrm{C}$; rapid freezing to $-187^{\circ} \mathrm{C}$ was then carried out by immersing the cryules in liquid nitrogen. Rewarming of the islets was performed by immersion of the cryules in a water bath at $37.4^{\circ} \mathrm{C}$. As there are few reports of cryopreservation of isolated islets we chose the above freezing programme simply because it is known to produce a high yield of viable lymphocytes [7], when used by our colleagues in the Department of Anatomy, University of Newcastle upon Tyne.

In Group II, islets obtained from eight animals were frozen at a rate of $5^{\circ} \mathrm{C} / \mathrm{min}$ to $-50^{\circ} \mathrm{C}$; rapid freezing to $-187^{\circ} \mathrm{C}$ was performed by immersion of the cryules in liquid nitrogen. Following rewarming the islets were cultured for a period of 14-24 $\mathrm{h}$ in Falcon tissue culture flasks containing $15 \mathrm{ml}$ freshly made R.F. 10 medium. Storage periods at $-187^{\circ} \mathrm{C}$ in both groups varied from one to two weeks. No attempt was made to control this storage period as there is good evidence in the literature which suggests that it does not influence survival [8].

\section{Organ Culture of Isolated Islets}

We have used organ tissue culture dishes $(60 \times 15$ mm style with absorbent ring) obtained from Falcon, 1950 Williams Drive, Oxnard, CA93030, U.S.A. The outer well contains a ring of filter paper moistened to maintain humidity. The centre well contains freshly made tissue culture medium R.F.10. This medium was made up as follows: R. P. M. I $164090 \mathrm{ml}$, heat inactivated fetal calf serum $10 \mathrm{ml}, \mathrm{L}$-Glutamine 1.5 $\mathrm{ml} / 100 \mathrm{ml}$, penicillin and streptomycin solution $1 \mathrm{ml}$. The final glucose concentration of the medium was $200 \mathrm{mg} / 100 \mathrm{ml}$. All the constituents were obtained from Gibo Biocult Ltd., Paisley, England. A millipore filter (pore size $5 \mu \mathrm{m}$ ) was floated on the medium in the centre well and ten islets carefully transferred from the dissection well to the millipore filter. Strict aseptic precautions were observed during the microdissection and transfer. The lid of the chamber was replaced and the chamber carefully transferred to an airtight jar which was gassed with $95 \%$ air and $5 \%$ $\mathrm{CO}_{2}$. The jar was placed in an incubator at $37.4^{\circ} \mathrm{C}$. At 5 days half the medium was replaced with fresh R. F. 10. At seven days the medium was completely changed; thereafter replenishing of the medium was performed at five day intervals.

Islets were cultured for periods of 7 to 28 days.

\section{Assessment of Viability}

In the initial part of this study viability was assessed histologically by studying sections of the islets stained with Gomori's aldehyde fuchsin [2] using either an orange $\mathrm{G}$ light green counterstain or a phloxine fast green counterstain. Using the differential stains described A- and B-cells can easily be recognised.

Histological survival has been defined as the presence of at least $50 \%$ of islets in any one experiment fulfilling the following criteria:

1) No disruption of cell membranes

2) No nuclear pyknosis

3) No gross enlargement of the cytoplasm

4) A normal configuration of the nucleoli

In the majority of the experiments all ten islets were examined but, in approximately $20 \%$, islets were 'lost', probably due to adherence to the walls of the 
perifusion chamber. This loss was never greater than three islets in any one experiment.

Functional studies were performed using a perifusion system.

\section{Histological Techniques}

Histological processing of such small volumes of tissue posed initial problems that were overcome by processing the islets on millipore filters.

\section{Control Pancreas}

From each donor a small piece of whole pancreas was fixed in Bouin's before the microdissection was commenced. This served as control. For pieces measuring $1 \mathrm{~cm} \times 1 \mathrm{~cm}$ a $24 \mathrm{~h}$ fixation period was found to be adequate. After fixation dehydration through the alcohols was performed with final embedding in wax. Sections were cut a $7 \mu \mathrm{m}$ and stained with Gomori's aldehyde fuchsin [2].

\section{Islets after Preservation}

Following preservation the islets were fixed in Bouin's for $30 \mathrm{~min}$. Dehydration through the alcohols was then performed together with the filter paper. Islets plus filter were finally embedded in wax and sectioned at $5 \mu \mathrm{m}$ and stained as in the control.

\section{Perifusion of Islets}

Viable pancreatic islets will respond in vitro to a glucose stimulus by a typical biphasic release of insulin [9]. Viability of islets after preservation has been assessed using a perifusion system similar to that described by Hoshi et al. [9]. Although the biphasic response is described as being characteristic it is difficult to produce a quantitative reproducibility of this response unless the insulin output is related to the absolute weight of islet tissue perifused. In our experiments we were unable to do this and as the size of the islets varied considerably we have accepted a three to four fold increase in stimulated insulin levels over the basal, together with the presence of a stimulation plateau, as shown in Fig. 1, as being evidence of a positive response.

Microdissected islets were transferred to a millipore chamber using a wire loop. In each case ten islets were placed on a millipore filter (pore size $5 \mu \mathrm{m}$ ) contained in the chamber. The chamber was connected to the perifusion circuit and submersed in a water bath at $37.4^{\circ} \mathrm{C}$. A Krebs Ringer bicarbonate buffer solution containing $100 \mathrm{mg} / 100 \mathrm{ml}$ of glucose was passed through the chamber at a constant flow rate of $0.5 \mathrm{ml} / \mathrm{min}$. A gas mixture of $95 \%$ air and $5 \%$ $\mathrm{CO}_{2}$ was continuously bubbled through the buffer solution in its reservoir. Samples of perifusate were collected at 5 minute intervals for 40 minutes using a

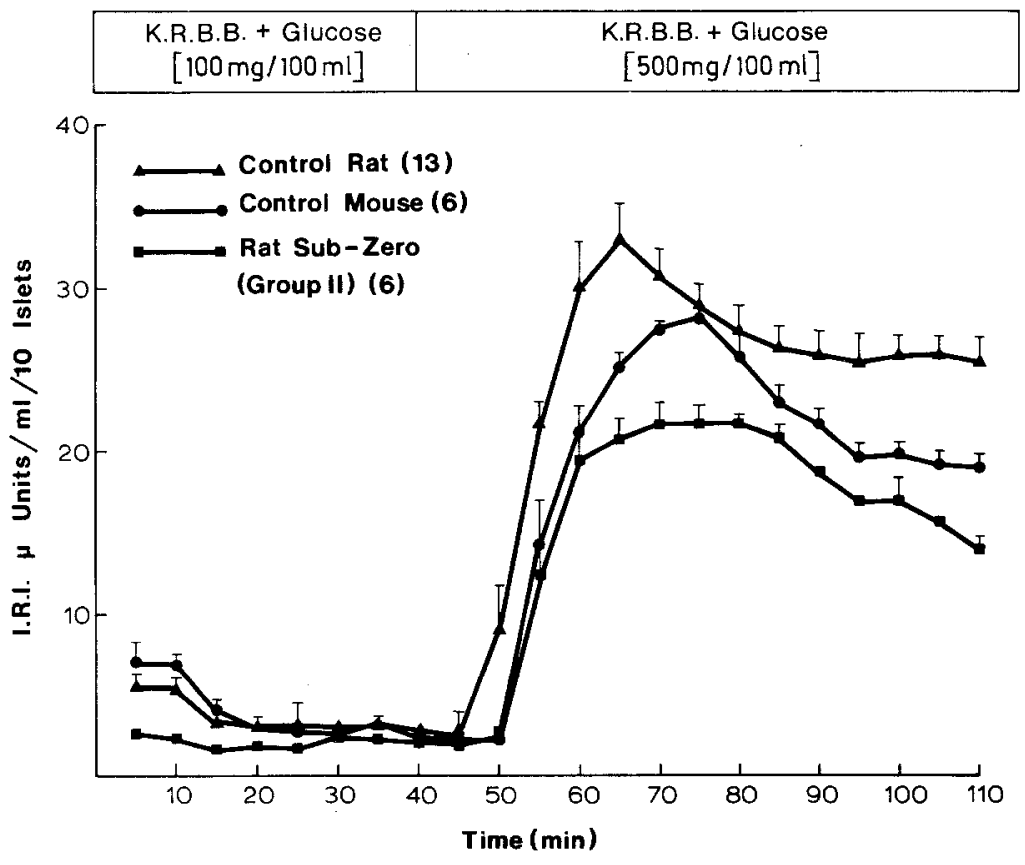

Fig. 1. Shows the response of freshly isolated islets and the Group II cryopreserved islets to a glucose stimulus in vitro. The mean values have been plotted and vertical bars represent \pm S E M 
fraction collector. After 40 minutes basal perifusion the perifusate was changed to one containing 500 $\mathrm{mg} / 100 \mathrm{ml}$ glucose. Fractions were collected at intervals and assayed for insulin using a single antibody radio-immunoassay, with mouse and rat standards obtained from Novo Laboratories, Copenhagen. Guinea pig insulin does not cross react with other insulins; therefore no perifusions were performed on guinea pig islets.

\section{Results}

\section{Fresh Control Islets (Fig. I)}

Islets were isolated from 15 control rats and 6 control mice. Immediately after isolation a group of islets were fixed for histological examination. Ten islets from each were perifused and the insulin output measured (Fig. 1.). During the basal perifusion several samples showed initial raised levels of insulin which decreased rapidly. This is thought to be due to a "washout" phenomenon of performed insulin. When the perifusate is changed to one containing 500 $\mathrm{mg} / 100 \mathrm{ml}$ glucose there is a delay of some ten minutes before insulin levels increase. This is partly explained by the 'dead space' of the apparatus which has been measured at $4 \mathrm{ml}$. At $60-80 \mathrm{~min}$ peak levels of insulin output are shown with a plateau occurring at approximately $90 \mathrm{~min}$.

Histologically, freshly isolated islets showed minimal damage, which may be secondary to mechanical trauma sustained during microdissection. The cells were slightly degranulated when compared with islets seen in sections of the control fixed whole pancreas. In 13 of 15 experiments rat islets were shown to respond to a glucose stimulus in vitro by a release of insulin. In the two cases that did not respond the microdissection procedure had been difficult and the dissection time was prolonged, $65 \mathrm{~min}$ and $75 \mathrm{~min}$ respectively. Islets from all 6 mice responded to a glucose stimulus.

\section{Simple Cold Storage of Islets}

Microdissected islets from guinea pig, rat and mouse have been stored for periods of 15 to $72 \mathrm{~h}$ in Hank's balanced salt solution (containing $100 \mathrm{mg} / 100 \mathrm{ml} \mathrm{glu}-$ cose) at $4^{\circ} \mathrm{C}$. Their survival is shown in Table 1 . After $15 \mathrm{~h}$, histological and functional survival was $100 \%$. Figure 2 shows a rat islet after $15 \mathrm{~h}$ storage. More than $50 \%$ of the A- and B-cells look histologically normal but the B-cells show marked degranulation when compared with the controls. At $24 \mathrm{~h}$ in the guinea pig there were $2 / 6$ histologic survivors. In the rat $4 / 8$ were classified as histologically surviving but only $1 / 8$ showed a positive response in the perifusion system. In the mouse histological survival was $7 / 8$ and functional survival $4 / 8$. Increasing the storage period produced progressive histologic damage.

At $48 \mathrm{~h}$ only one histological survival was noted in the rat. There were no surviving islets following $72 \mathrm{~h}$ storage.

\section{Sub Zero Cell Storage in Liquid Nitrogen at $-187^{\circ} \mathrm{C}$}

The results are shown in Table 2 and Figure 1. In Group I, islets from two mice were completely necrotic following storage at $-187^{\circ} \mathrm{C}$.

In the rat, however, histological survival was noted in 4/11 cases and functional survival in $2 / 11$.

In Group II, histological survival was noted in $7 / 8$ cases and functional survival in $6 / 8$.

Figure 3 shows a rat islet following sub zero cell storage. A- and B-cells can be recognised. The B-cells appear to encircle a capillary and a degenerating cell is shown in the top right corner of the photomicrograph. Stimulated levels of insulin from the Group II islets are slightly less than those in the controls (Fig. 1).

Table 1. Storage of islets at $4^{\circ} \mathrm{C}$ in Hank's B.S.S.

\begin{tabular}{|c|c|c|c|c|c|c|c|c|}
\hline & $15 \mathrm{~h}$ & & $24 \mathrm{~h}$ & & $48 \mathrm{~h}$ & & $72 \mathrm{~h}$ & \\
\hline & H. S & F.S. & $\overline{\text { H.S }}$ & F. S. & H. S. & F. S. & $\overline{\mathrm{H} . \mathrm{S}}$ & F. S. \\
\hline Guinea Pig & - & - & $2 / 6$ & - & $0 / 1$ & - & $0 / 2$ & - \\
\hline Rat & $2 / 2$ & $2 / 2$ & $4 / 8$ & $1 / 8$ & $1 / 10$ & $1 / 10$ & $0 / 6$ & $0 / 6$ \\
\hline Mouse & - & - & $7 / 8$ & $4 / 8$ & $0 / 2$ & $0 / 2$ & $0 / 6$ & $0 / 6$ \\
\hline
\end{tabular}

H. S. - Histologic survival - See Materials \& Methods.

F. S. - Functional survival - Four fold increase in basal insulin levels in response to a glucose stimulus.

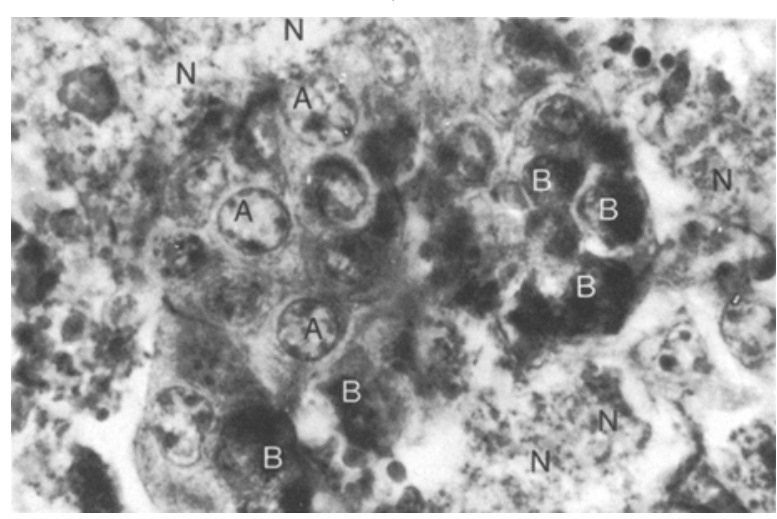

Fig. 2. Islet after $15 \mathrm{~h}$ storage at $4^{\circ} \mathrm{C}$. Necrotic cells (N) are present at the periphery of the islet. Using the differential stain A- and $B$-cells can easily be identified. The B-cells are degranulated when compared with the controls. Gomori's aldehyde fuchsin. Approx. Mag. $\times 1750$ 


\section{Organ Culture of Islets}

Islets from the guinea pig, rat and mouse have been cultured as described for periods of 7 to 28 days. Survival is shown in Table 3.

At 7 days $100 \%$ histological survival was noted. This dropped to approximately $80 \%$ at 21 days and to $33 \%$ at 28 days. In organ culture during the first 7 days the islets tended to become more spherical and the B-cells showed degranulation, confirming the observations of Moskalewski [10]. At 28 days fibroblastic overgrowth was observed and the capsules of several islets appeared to have ruptured, with the subsequent outgrowth of islet cells as a monolayer on the filter paper. Increasing the culture period tended to increase the number of damaged islet cells which were usually seen at the periphery or within the centre of the islet. No mitotic figures were seen in any of the cultures. Of 62 culture experiments performed perifusions were carried out in 39 . In no case could we show a positive response.

\section{Discussion}

Viable pancreatic islets can be isolated from the mouse, rat and guinea pig using a free hand microdissection procedure. In the fresh state they appeared histologically normal and responded to a glucose stimulus in vitro with at least a 3-4 fold increase in insulin output. The main criticism of microdissection is that the yield of islets from any one pancreas is low. If satisfactory long term preservation methods could be established, small yield would no longer be a serious problem. There have been numerous reports of the successful preservation of isolated islets by simple cold storage [11], cryopreservation [12] and by tissue culture techniques $[10,13]$. The majority of these investigations have used collagenase isolated islets and may not be comparable with the results of our experiments using microdissected islets.

We have described the histological and functional survival of microdissected islets subjected to three preservation systems:

\section{a) Simple Cold Storage}

Knight et al [11] reported the successful storage of collagenase isolated islets for up to $48 \mathrm{~h}$ in a balanced salt solution at $4^{\circ} \mathrm{C}$. We have not been as successful, noting only one instance of functional survival at $48 \mathrm{~h}$. It would appear from our results that this method may provide a suitable system for the short term preservation of islets for up to $12 \mathrm{~h}$. In the clinical situation we really cannot see this as being of any practical value, but if methods become available for harvesting large numbers of islets from any one pancreas it may prove useful for the short term storage of those required before a transplant could be performed.

\section{b) Sub Zero Cell Storage}

Cryopreservation is a relatively new field and one that is fraught with numerous difficulties including freezing rates, rewarming rates, the use of different cryoprotective agents and also the fact that different tis-

Table 2. Storage of islets at $-187^{\circ} \mathrm{C}$

\begin{tabular}{llllll}
\hline & Group I & & \multicolumn{2}{c}{ Group II } \\
\cline { 2 - 3 } & H. S. & F. S. & & H. S. & F. S. \\
\hline Mouse & $0 / 2$ & - & & - & - \\
Rat & $4 / 11$ & $2 / 11$ & & $7 / 8$ & $6 / 8$ \\
\hline
\end{tabular}

Group I Freezing rate of $1^{\circ} \mathrm{C} / \mathrm{min}$ followed by rapid rewarming in water bath at $37.4^{\circ} \mathrm{C}$.

Group II Freezing rate of $5^{\circ} \mathrm{C} / \mathrm{min}$ followed by rapid rewarming in water bath followed by a $24 \mathrm{~h}$ culture period.

H. S. - Histologic survival

F. S. - Functional survival

Table 3. Organ culture of isolated islets

\begin{tabular}{|c|c|c|c|c|c|c|c|}
\hline & $\frac{7 \text { days }}{\text { H. S. F.S. }}$ & $\frac{14 \mathrm{da}}{\mathrm{H} . \mathrm{S} .}$ & $\frac{y s}{\text { F. S. }}$ & $\frac{21 \mathrm{da}}{\mathrm{H} . \mathrm{S} .}$ & $\frac{y s}{\text { F. S. }}$ & $\frac{28 \mathrm{da}}{\text { H. S. }}$ & 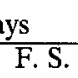 \\
\hline Guinea Pig & $10 / 11-$ & $3 / 4$ & - & $1 / 1$ & - & $3 / 6$ & - \\
\hline Rat & $6 / 6 \quad 0 / 5$ & $5 / 6$ & $0 / 6$ & $5 / 6$ & $0 / 6$ & $2 / 7$ & $0 / 7$ \\
\hline Mouse & $2 / 2 \quad 0 / 2$ & $2 / 2$ & $0 / 2$ & $4 / 5$ & $0 / 5$ & $2 / 6$ & $0 / 6$ \\
\hline
\end{tabular}

H. S. - Histologic Survival

F. S. - Functional Survival

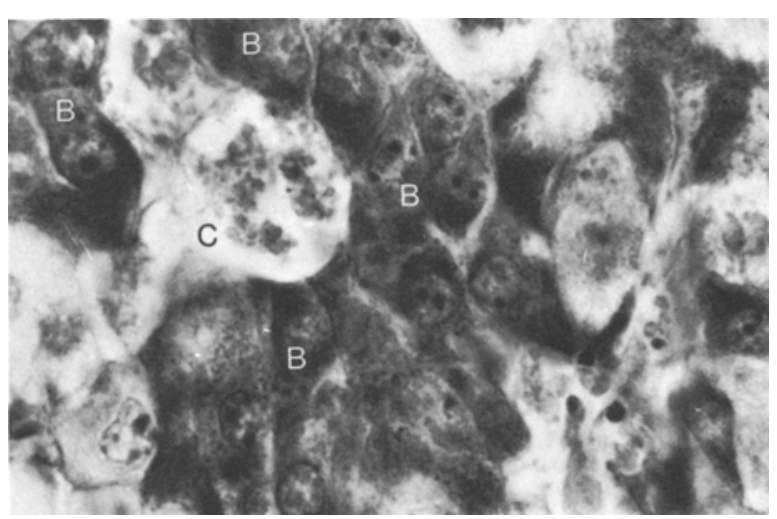

Fig. 3. Surviving rat islet following storage at $-187^{\circ} \mathrm{C}$. A group of histologically undamaged B-cells can be seen closely surrounding a capillary. Gomori's aldehyde fuchsin. Approx: Mag. $\times 1750$ 
sues show differing susceptibility to freezing injury. Cell damage occurs during freezing and rewarming. At $-187^{\circ} \mathrm{C}$ molecular motion is almost completely inhibited and, theoretically, ageing and degeneration of cells should be prevented. Eijsvoogel et al. [8] have shown that the length of storage at $-187^{\circ} \mathrm{C}$ has no effect on the functional properties of cryopreserved lymphocytes in vitro. Our experiments have shown that in the Group I animals, functional survival was only demonstrated in $2 / 11$ cases. We have shown that survival is significantly increased to approximately $75 \%$ by using a freezing rate of $5^{\circ} \mathrm{C} / \mathrm{min}$, with $10 \%$ D.M.S.O., followed by a $24 \mathrm{~h}$ culture period after rewarming. We are unable to distinguish between the effect of faster cooling, the culture period, or a combination of the two as being responsible for the greater relative success of Group II over Group I.

Knight [12] quotes freezing rates varying between $1^{\circ} \mathrm{C} / \mathrm{min}$ and $10^{\circ} \mathrm{C} / \mathrm{min}$ down to $-8^{\circ} \mathrm{C}$. It has been stated by Leibo [14] that the survival of marrow stem cells is maximal at a cooling rate that depends on the cryoprotective agent used and its concentration. They have also shown that the survival of cells using $0.4 \mathrm{M}$ glycerol is not affected by cooling rates varying between $2^{\circ} \mathrm{C} / \mathrm{min}$ and $10^{\circ} \mathrm{C} / \mathrm{min}$. In both experimental groups we have used the same concentration of D.M.S.O. and it may be that our increased freezing rate of $5^{\circ} \mathrm{C} / \mathrm{min}$ is not responsible for the increased survival.

\section{c) Organ Culture}

Moskalewski [10] has reported histological survival of guinea pig islets following fourteen days tissue culture. The main morphological changes observed were related to degranulation of the B-cells. Andersson [13] reported on the long term effects of glucose on insulin release and glucose oxidation by mouse pancreatic islets maintained in tissue culture. He showed that islets cultured for six days at a physiological glucose concentration produced insulin in a manner similar to that observed for freshly isolated islets. For freshly isolated, non-cultured islets, there was a sigmoid dose-response curve with maximal stimulation at about $20 \mathrm{mM}$ glucose.

We have shown that islets from the guinea pig, rat and mouse suffer minimal morphologic damage when cultured for 21 days in a simple organ culture system. Increasing the culture period to 28 days produced progressive histologic damage. We have not been able to correlate histologic findings with functional survival using the perifusion system in any of our cultures. No scientific explanation for this failure can be offered, but it may be that the artificial nature of organ culture has in some way affected either the synthesis or re- lease of insulin in response to a glucose stimulus. The tissue culture medium used in our experiments contained the indicator phenol red, which only shows gross alterations in $\mathrm{pH}$ occurring during culture. It is possible, that minor alterations in $\mathrm{pH}$ have occurred and that these may be responsible for the lack of a functional response to a glucose stimulus. We have recently observed [15] that collagenase and microdissected islets from the rat fail to respond to a glucose stimulus if the $\mathrm{pH}$ of Hank's solution used during isolation falls below 6.8. It is also of interest to note that a great number of the reports of successful islet cell culture are of islets isolated by the collagenase technique.

We are pursuing this work and also subjecting microdissected human islets to the three described preservation systems.

In the clinical context organ culture deserves urgent further investigation, as theoretically the antigenicity of tissues in culture may be modified [16].

Acknowledgements. This work was carried out in the Department of Surgery, Royal Victoria Infirmary, during the tenure of a Wellcome Surgical Training Fellowship. We wish to thank Mr. M. White for expert technical assistance and also Mr. J. B. Leyfield, of the Department of Anatomy, University of Newcastle upon Tyne, who provided the photomicrographs. We also wish to thank Professor J. T. Owen and the staff of the Anatomy Department who gave expert advice on the techniques of organ culture and cryopreservation.

\section{References}

1. Hellerström, C.: A method for the microdissection of intact pancreatic islets in mammals. Acta endocr. (Kbh.) 45, 122-131 (1964)

2. Gomori, G.: Aldehyde fuchsin: A new stain for elastic tissue. Amer. J. clin. Path. 20, 656-666 (1950)

3. Ballinger, W.F., Lacy, P.E.: Transplantation of intact pancreatic islets in rats. Surgery 72, 175-186 (1972)

4. Kemp, C. B., Knight, M.J., Scharp, D.W., Lacy, P.E., Ballinger, W.F.: Transplantation of isolated pancreatic islets into the portal vein of diabetic rats. Nature 244, 447-449 (1973)

5. Lacy, P. E., Kostianovsky, M.: Method for the isolation of intact islets of Langerhans from the rat pancreas. Diabetes 16, 35-39 (1967)

6. Ruiz, J.O., Lillehei, R.C.: In: Organ preservation for transplantation (eds. A.H. Karow, G.J.M. Abouna, A. L. Humphries), p. 380. Boston: Little Brown and Company 1974

7. Birchall, J.: Personal communication 1975

8. Eijsvoogel, V.P., du Bois, M.J.G.J., Wal. r.v.d. Huismans, D. R., Raat - Koning, L.: Cryopreserved lymphocytes: Functional properties in vitro. In: The cryopreservation of normal and neoplastic cells (eds. R.S. Weines, R.K. Oldham, L. Schwarzenberg), pp. 101-106. Inserm. 1973

9. Hoshi, M.C., Shreeve, W.W.: Release and production of insu- 
lin by isolated perifused rat pancreatic islets. Control by glucose. Diabetes 22, 16-23 (1973)

10. Moskalewski, S.: Studies on the culture and transplantation of isolated islets of Langerhans of the guinea pig. Proc. kon. ned. Akad. Wet. 72, 156 (1969)

11. Knight, M.J., Scharp, D.W., Kemp, C.B., Ballinger, W.F., Lacy, P.E.: Effects of cold storage on the function of isolated pancreatic islets. Cryobiology 10, 89-90 (1973)

12. Knight, M. J.: Communication to the European Society of Experimental Surgery, Salzburg, May 14th, 1974

13. Andersson, A.: Long term effects of glucose on insulin release and glucose oxidation by mouse pancreatic islets maintained in tissue culture. Biochem. J. 140, 377-382 (1974)

14. Leibo, S. P., Farrant, J., Mazur, P., Hanna, M. G., Smith, L. H.: Effects of freezing on marrow stem cell suspensions. Interactions of cooling and warming rates in the presence of PVP, sucrose or glycerol. Cryobiology 6, 315-332 (1970)
15. Craik, M., Higgs, M. J., Ferguson, J.: Unpublished observations 1975

16. Boyles, R.R., Seltzer, H.S.: Reversal of alloxan diabetes in non-inbred rats. Diabetes 24 (Suppl. 2), 420 (1975)

Received: October 6, 1975, and in revised form: January 12, 1976

Mr. J. Ferguson

Dept. of Surgery

Univ. of Newcastle upon Tyne

Newcastle upon Tyne, NE $14 \mathrm{LP}$

England 